Check for updates

Cite this: Chem. Commun., 2020,

56,2646

Received 30th October 2019

Accepted 13th January 2020

DOI: $10.1039 /$ c9cc08468a

rsc.li/chemcomm

\section{Janus bis(NHCs) tuned by heteroatom-bridge oxidation states $\dagger$}

\author{
Nabila Rauf Naz, ${ }^{a}$ Gregor Schnakenburg, (D) ${ }^{a}$ Antal Mikeházi, (DD ${ }^{\mathrm{b}}$ Zsolt Kelemen, (D) ${ }^{\mathrm{b}}$ \\ László Nyulászi, (D) ${ }^{\mathrm{b}}$ René T. Boeré (D) ${ }^{\mathrm{c}}$ and Rainer Streubel (D) *a
}

Synthesis of the first tricyclic bis(carbenes) with facially opposed imidazole-2-ylidenes and two linking phosphorus centres in different oxidation states is presented using a modular, high-yield synthetic route. The formation of homo bimetallic coinage metal complexes provides a glimpse on their potential use.

$\mathrm{N}-\mathrm{Heterocyclic}$ carbenes (NHCs) I were proposed as transient species more than a half century ago, ${ }^{1}$ but it was Arduengo ${ }^{2 a}$ who achieved the breakthrough of synthesizing the first stable cyclic carbene, following closely on the first isolable carbene stabilized by $\mathrm{P}^{\mathrm{III}}{ }^{2 b}$ This achievement initiated an impressive development in imidazole-2-ylidene chemistry (Fig. 1), and beyond. ${ }^{3}$ More recently, NHC chemistry became sophisticated enough to build ligands possessing structural diversities and catalytic functionalities, ${ }^{4}$ applicable in coordination chemistry, ${ }^{5}$ homogeneous catalysis, ${ }^{6}$ and organocatalysis. ${ }^{7}$ Modification of electronic properties of NHCs, became a primary issue and various concepts were followed, i.e., $\mathrm{N}$-substituent design or annellation with the imidazole ring, ${ }^{8}$ but also to exert electronic influence ${ }^{9}$ via NHC backbone substituents. ${ }^{10}$

In case of the latter, the initial focus was on mono-NHCs bearing substituents derived from heteroatoms such as $\mathrm{Cl}^{11}$ $\mathrm{O},{ }^{12} \mathrm{~N}^{13} \mathrm{Si}^{14}{ }^{14}{ }^{15}{ }^{15}$ and $\mathrm{P} .{ }^{16}$ In contrast, knowledge about $[a, d]$ benzannulated "ditopic" Janus bis(NHCs) III, first reported by Bielawski et al. ${ }^{17}$ remains scarce. Coordination properties were investigated by Peris and used to build novel organometallic

\footnotetext{
${ }^{a}$ Institut für Anorganische Chemie der Rheinischen Friedrich-Wilhelms-Universität Bonn, Gerhard-Domagk-Strasse 1, 53121 Bonn, Germany. E-mail: r.streubel@uni-bonn.de; Web: http://anorganik.chemie.uni-bonn.de/akstreubel

${ }^{b}$ Department of Inorganic and Analytical Chemistry and MTA-BME Computation Driven Chemistry Research Group, Budapest University of Technology and Economics, Szt Gellert ter 4, 1111 Budapest, Hungary.

E-mail:nyulaszi@mail.bme.hu

${ }^{c}$ Department of Chemistry and Biochemistry, University of Lethbridge, 4401 University Drive West, Lethbridge, AB, T1K3M4, Canada. E-mail: boere@uleth.ca

$\dagger$ Electronic supplementary information (ESI) available. CCDC 1919566-1919569. For ESI and crystallographic data in CIF or other electronic format see DOI: $10.1039 / \mathrm{c} 9 \mathrm{cc} 08468 \mathrm{a}$
}
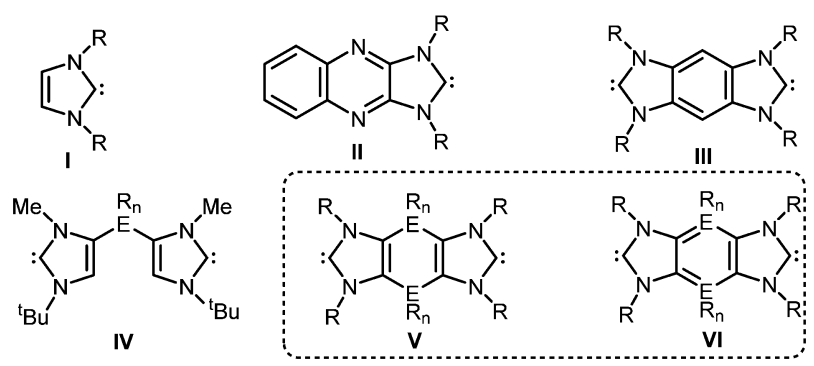

Fig. 1 Mono NHCs I and II, Bielawski bis(NHCs) III and E-bridged bis(NHCs) IV-VI ( $\mathrm{E}=$ main group element).

architectures. ${ }^{18}$ Hahn and co-workers created molecular squares and quadrilaterals in supramolecular assemblies. ${ }^{19}$ Mono-NHCs I and flexible bis(NHCs) IV having phosphorus as heteroatom bound to the backbone and possessing different oxidation states were studied, ${ }^{16,20}$ but rigid, heteroatom-linked bis(NHCs) such as $\mathbf{V}$ and VI (Fig. 1) are almost unknown. ${ }^{20 c}$ This is surprising as the incorporation of hetero-atoms would not just enable unprecedented chemical diversity but also a functional entity that could be redox active and/or possess further, different donor centres. The recent report on tricyclic 1,4-dihydro-1,4-diphosphinines ${ }^{21}$ bearing dithione functionalities constituted an interesting conceptional starting point for the synthesis of P-functional bis(NHCs).

Herein, synthesis of the first tricyclic $\mathrm{P}^{\mathrm{V} / \mathrm{V}}$ - and $\mathrm{P}^{\mathrm{III} / \mathrm{III}}$-bridged bis(imidazole-2-ylidenes) and their use to form dinuclear coinage metal(I) complexes is reported. Structural and electronic properties of the free ligands and their bimetallic complexes are discussed using combined DFT and CV results.

As our initial studies of the oxidative desulfurization of tricyclic 1,4-dihydro-1,4-diphosphinine dithiones failed, we considered synthesizing and employing the corresponding diselones. The tricyclic $\mathrm{P}^{\mathrm{III} / \mathrm{III}}$-bridged diselone $\mathbf{1}$ was obtained as cis/trans mixture $(1: 0.7)$ in good yields after work-up using previously published protocols. ${ }^{21,22}$ In this case we could also separate the cis and trans isomers using low-temperature column chromatography, thus being able to fully characterize $\mathbf{1}^{\text {cis }}$ and, hence, assigning the ${ }^{31} \mathrm{P}$ resonance signal at $0.91 \mathrm{ppm}$ to the $c i s$, and at $3.75 \mathrm{ppm}$ to 


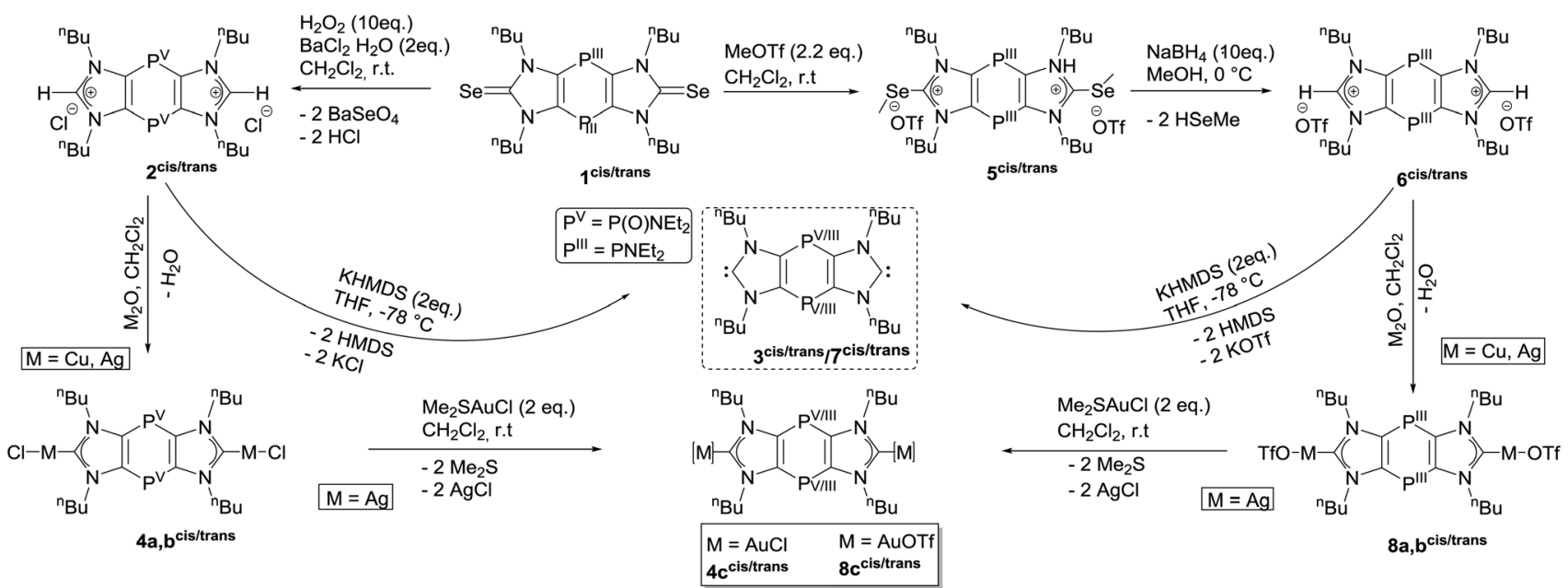

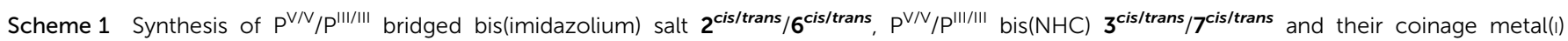
complexes $4 a-c^{c i s / t r a n s} / 8 a-c^{c i s / t r a n s}$.

the trans isomer. $\mathbf{1}^{c i s}$ was also structurally confirmed (see ESI $\dagger$ ). Starting from $1^{\text {cis/trans }}$ and using 10 eq. of $\mathrm{H}_{2} \mathrm{O}_{2}$ in dichloromethane, the isomeric $\mathrm{P}^{\mathrm{V} / \mathrm{V}}$-bridged bis(imidazolium) salts $(1: 0.9)$ were formed via oxidative deselenization, ${ }^{23}$ and immediate treatment with $\mathrm{BaCl}_{2} \cdot 2 \mathrm{H}_{2} \mathrm{O}$ led to the chloride salts $2^{\text {cis/trans }}$ (Scheme 1). The oxidation of the $\mathrm{P}^{\mathrm{III} / \mathrm{III}}$ to $\mathrm{P}^{\mathrm{V} / \mathrm{V}}$ centres was revealed by ${ }^{31} \mathrm{P}$ resonances of $\delta=-6.2$ (cis) and -5.6 (trans). Formation of the $\mathrm{P}^{\mathrm{V} / \mathrm{V}}$ bis(imidazolium) derivative $2^{\text {cis/trans }}$ was confirmed by various analytical methods and an XRD structure (see ESI†).

Tricyclic $\mathrm{P}^{\mathrm{V} / \mathrm{V}}$-bridged bis(imidazolium) salts $2^{\text {cis/trans }}$ were converted into $\mathrm{P}^{\mathrm{V} / \mathrm{V}}$-bis(NHCs) $3^{\text {cistrans }}(1: 0.2)$ in overall $88 \%$ yield by deprotonation using two eq. of KHMDS in THF (Scheme 1). The ${ }^{31} \mathrm{P}\{\mathrm{H}\}$ NMR spectrum of $3{ }^{\text {cis/trans }}$ revealed resonances at -2.4 (cis) and -1.2 (trans) ppm, only slightly downfield shifted compared to $2^{\text {cis/trans }}$. The absence of $\mathrm{C}^{2}$-proton resonances in the ${ }^{1} \mathrm{H}$ NMR spectrum and the typical downfield shift of the $\mathrm{C}^{2}$-carbon resonances at $225.0 \mathrm{ppm}^{17}$ in the ${ }^{13} \mathrm{C}\left\{{ }^{1} \mathrm{H}\right\}$ NMR spectrum of $3^{\text {cis/trans }}$ provided firm NMR spectroscopic evidence for the biscarbenes (for further details see ESI $\dagger$ ).

The molecular structure of $3^{\text {trans }}$ (Fig. 2) possesses an N1-C3-N2 bond angle of $102.4(11)^{\circ}$, slightly more acute than in (imidazole-2-ylidenes) $\mathbf{I}\left(\mathrm{R}=\mathrm{Ad}\right.$ or $t \mathrm{Bu}, 104.4^{\circ}$ or $\left.104.8^{\circ}\right) .^{24}$

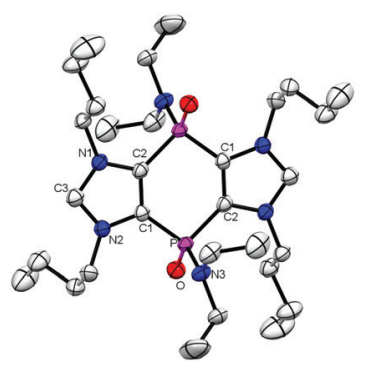

Fig. 2 Molecular structure of compound $3^{\text {trans }}$ (ellipsoids at the $50 \%$ probability level); hydrogen atoms are omitted for clarity. Selected bond lengths [Å] and angles [']: C3-N1 1.368(17), C3-N2 1.367(17), N2-C1 1.397(16), N1-C2 1.396(16), C1-C2 1.368(17), C1-P 1.792(13), P-O 1.477(9), $\mathrm{P}-\mathrm{N} 3$ 1.645(11); N1-C3-N2 102.4(11),C1-P-C2 ${ }^{1} 101.1(6)$.
M06-2X/6-31+G* DFT calculations on $3^{\text {icis/trans } 25}$ indicate a $0.5 \mathrm{kcal} \mathrm{mol}^{-1}$ preference for the trans isomer. For both isomers $\left(3^{\text {'cis/trans }}\right.$ ), the $\pi$-type LUMO (Fig. 4) is delocalized over the central ring and the HOMO $(\varepsilon=-6.17 \mathrm{eV})$ for the trans isomer and $\varepsilon=-6.19 \mathrm{eV}$ for the cis isomer are antibonding combinations of the two weakly coupled (Fig. S55 of the ESI $\dagger$ ) in-plane carbene lone pairs (Fig. 4). In accordance with the acute bond angle, they have strong s-character $\left(51.7 \%\right.$ at $\mathrm{B} 3 \mathrm{LYP} / 6-31+\mathrm{G}^{* *} / / \mathrm{M} 06-2 \mathrm{X} / 6-31+\mathrm{G}^{*}$, comparable to $53.0 \%$ in $\mathrm{PH}_{3}$, see Fig. 4). To assess the stability of the tricyclic carbenes, we investigated the isodesmic reaction: $\mathrm{R}^{\prime} \mathrm{R}^{\prime \prime} \mathrm{C}:+\mathrm{CH}_{4} \rightarrow \mathrm{R}^{\prime} \mathrm{R}^{\prime \prime} \mathrm{CH}_{4}+\mathrm{CH}_{2}$ for $3^{\prime \text { cisitrans }}{ }^{26}$ For (N-methyl)imidazole-2-ylidene, $111.5 \mathrm{kcal} \mathrm{mol}^{-1}$, for $3^{\prime \text { cis }} 113.3$, and for $3^{\text {trrans }}$ $111.7 \mathrm{kcal} \mathrm{mol}^{-1}$ stabilization was obtained.

The NICS(0) values of the imidazole units are -10.5 for the cis and -10.9 for the trans isomer, indicating slightly reduced aromaticity compared to the parent imidazole-2-ylidene $(\mathrm{NICS}(0)=$ $-11.3)$ middle ring is about nonaromatic as indicated by the small positive NICS(0) values ( 0.5 for $3^{\prime c i s}$ and 0.1 for $3^{\text {trans }}$ ). Also the 89.9(cis) / 94.1(trans) measured ${ }^{77}$ Se chemical shift of derivative $3^{\text {cis/trans }}=\mathrm{Se}$, is somewhat more negative than for 1,3 -diisopropyl-imidazole-2-selone ( $-3 \mathrm{ppm}$ ), and comparable to 1,3-dippimidazole-2-selone $(87.0 \mathrm{ppm}){ }^{27}$

The $\mathrm{P}^{\mathrm{V} / \mathrm{V}}$-bridged bis(imidazolium) salts $2^{\text {cis/trans }}$ reacted in dichloromethane with one eq. of $\mathrm{M}_{2} \mathrm{O}(\mathrm{M}=\mathrm{Cu}, \mathrm{Ag})$ led to $\mathrm{P}^{\mathrm{V} / \mathrm{V}_{-}}$ bridged bis(NHC complexes) $\mathbf{4} \mathbf{a}^{-\mathbf{b}^{\text {cis/trans }}}$ while $\mathbf{4} \mathbf{c}^{\text {cis/trans }}$ was synthesized by metal exchange reaction with complex $\mathbf{4} \mathbf{b}^{\text {cis/trans }}$. All complexes $4 \mathbf{a}-\mathbf{c}^{c i s / t r a n s}$ were obtained as white powders and were fully characterized (see ESI $\dagger$ and Table 1). The molecular structure of $\mathbf{4 c}^{\text {trans }}$ from XRD (Fig. 3) shows an almost perfect colinear arrangement of the two $\mathrm{C}^{2}$-Au1 bonds of different molecules. The $\mathrm{C}^{2}$-Au1-Cl1 axis seem to deviate only slightly from linearity ( $c f$. ref. 11) and the trans-parallel orientation of two molecules of complex $\mathbf{4} \mathbf{c}^{\text {trans }}$ molecules indicate intermolecular aurophilic interactions in the solid state. Similar to the parent system, the trans isomer of the $\mathrm{Cu}$ complex $\mathbf{4} \mathbf{a}^{\prime}$ is calculated (at M06-2X/6-31+G*) to be more stable by $0.4 \mathrm{kcal} \mathrm{mol}^{-1}$, which holds true for all the metal complexes $(\mathrm{Cu}, \mathrm{Ag}$ and $\mathrm{Au})$. 
Table $1{ }^{31} \mathrm{P}\left\{{ }^{1} \mathrm{H}\right\}$ and ${ }^{13} \mathrm{C}\left\{{ }^{1} \mathrm{H}\right\}$ NMR data as well as isomer ratios for $\mathbf{2}^{\text {cis/trans }}$ $6^{\text {cis/trans }}, 3^{\text {cis/trans }}$ and $7^{\text {cis/trans }}$

\begin{tabular}{llll}
\hline & $\delta\left({ }^{31} \mathrm{P}\right) / \mathrm{ppm}\left(\mathrm{CD}_{2} \mathrm{Cl}_{2}\right)$ & $\delta\left({ }^{13} \mathrm{C}\right) / \mathrm{ppm}\left(\mathrm{CD}_{2} \mathrm{Cl}_{2}\right)^{c}$ & Ratio $^{d}$ \\
\hline $\mathbf{2}^{\text {ciss } \text { trans }}$ & $-6.2($ cis $),-5.9($ trans $)$ & $146.5\left(\mathrm{~d},{ }^{3} J_{\mathrm{P}, \mathrm{C}}=12.8 \mathrm{~Hz}\right)$ & $1: 0.9$ \\
$\mathbf{6}^{\text {cis } / \text { trans }}$ & $5.4($ cis $), 5.8($ trans $)$ & $141.0(\mathrm{~s})$ & $1: 0.3$ \\
$\mathbf{3}^{\text {cis/trans } a}$ & $-2.4($ cis $),-1.2($ trans $)$ & $225.0\left(\mathrm{t},{ }^{3} J_{\mathrm{P}, \mathrm{C}}=2.7 \mathrm{~Hz}\right)$ & $1: 0.7$ \\
$\mathbf{7}^{\text {cis } \text { trans } b}$ & $6.7($ cis $), 7.0$ (trans $)$ & $220.2\left(\mathrm{t},{ }^{3} J_{\mathrm{P}, \mathrm{C}}=2.4 \mathrm{~Hz}\right)$ & $1: 0.2$
\end{tabular}

${ }^{a}$ In case of $3^{\text {cis/trans }}, \mathrm{C}_{6} \mathrm{D}_{6} \cdot{ }^{b} 7^{\text {cis/trans }}$, THF- $\mathrm{d}_{8} \cdot{ }^{c} \mathrm{C}^{2}$ carbon. ${ }^{d}$ (cis/trans) ratios.

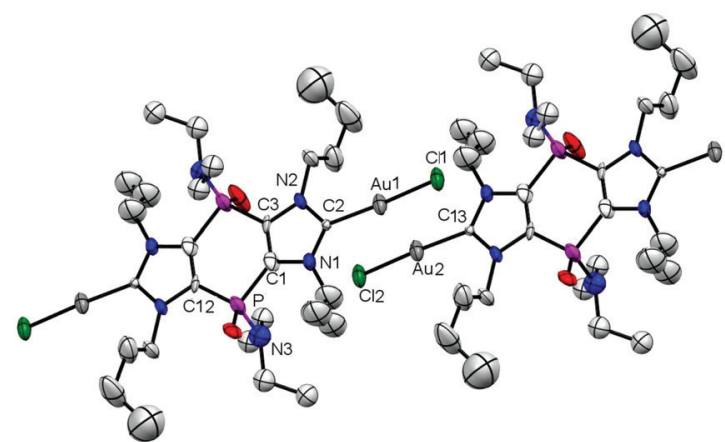

Fig. 3 Molecular structure of compound $4 \mathrm{c}^{\text {trans }}$ (ellipsoids at the $50 \%$ probability level) and hydrogen atoms are omitted for clarity (see ESI†).

It was obvious that the same protocol could not be used to access free $\mathrm{P}^{\mathrm{III} / \mathrm{III}}$-bridged bis(NHCs). Therefore, an initial twofold Se-methylation of $\mathbf{1}^{\text {cis/trans }}$ was considered. ${ }^{20 a}$ The salt $5^{\text {cis/trans }}$ was easily obtained $(84 \%$, ratio $1: 0.33)$ if 2 eq. of trifluoromethyl sulfonate (MeOTf) were used; for further details see ESI. $\dagger$ Subsequent use of $5^{\text {cis/trans }}$ and 5 eq. of $\mathrm{Na}\left[\mathrm{BH}_{4}\right]$ in methanol resulted in the formation of $\mathrm{P}^{\mathrm{III} / \mathrm{III}}$-bridged bis(imidazolium) salts $\mathbf{6}^{\text {cis/trans }}$ which could be isolated as an orange liquid $(61 \%, 1: 0.3)$ and were fully characterized; for selected NMR data, see Table 1.

The facile access to $6^{\text {cis/trans }}$ prompted us to target the $\mathrm{P}^{\mathrm{III} / \mathrm{III}}$ bridged bis(NHC) $7^{\text {cis/trans }}$ using 2 eq. of KHMDS in THF. The ${ }^{31} \mathrm{P}\left\{{ }^{1} \mathrm{H}\right\}$ NMR spectrum of the reaction mixture shows a slight downfield shift for the resonances of the new product $7^{\text {cis/trans }}$.

As for $3^{\text {cis/trans }}$ the energy difference between the two isomers of $7^{\prime \text { cis/trans }}$ is small $\left(0.8 \mathrm{kcal} \mathrm{mol}^{-1}\right)$, however, in case of $7^{\prime}$ the cis isomer is the more stable one. The inversion barrier of the phosphorus is high (44.2 $\left.\mathrm{kcal} \mathrm{mol}^{-1}\right)$, thus isomerization cannot be expected at room temperature. The stabilization energy of $7^{\prime}$ (111.1 kcal mol ${ }^{-1}$ for cis and $109.2 \mathrm{kcal} \mathrm{mol}^{-1}$ for trans) is also close to those of the parent imidazole-2-ylidene and $3^{\prime}{ }^{26}$ The aromaticity of the imidazole ring decreased somewhat according to the NICS(0) values $(-9.2$ for cis and -9.5 for trans) compared to $\mathbf{3}^{\prime \text { cis/trans }}$ (see NICS(1) values in the ESI $\dagger$ ). On the other hand the aromatic character of the middle ring increased slightly, which was indicated by the negative (although small) NICS(0) values $\left(-0.5\right.$ for $7^{\prime \text { cis }}$ and -0.9 for $\left.7^{\text {trans }}\right)$. Oxidation of $\mathrm{P}^{\mathrm{III}}$ centers was shown to increase antiaromaticity in phospholes, ${ }^{28}$ due to the increased involvement of $\sigma^{*}$ orbitals, which are significantly lower in energy for the $\mathrm{P}^{\mathrm{V}}$ system. ${ }^{29}$ Though the shape and the localization of HOMO and the LUMO of $7^{\text {cis/trans }}$ are similar to

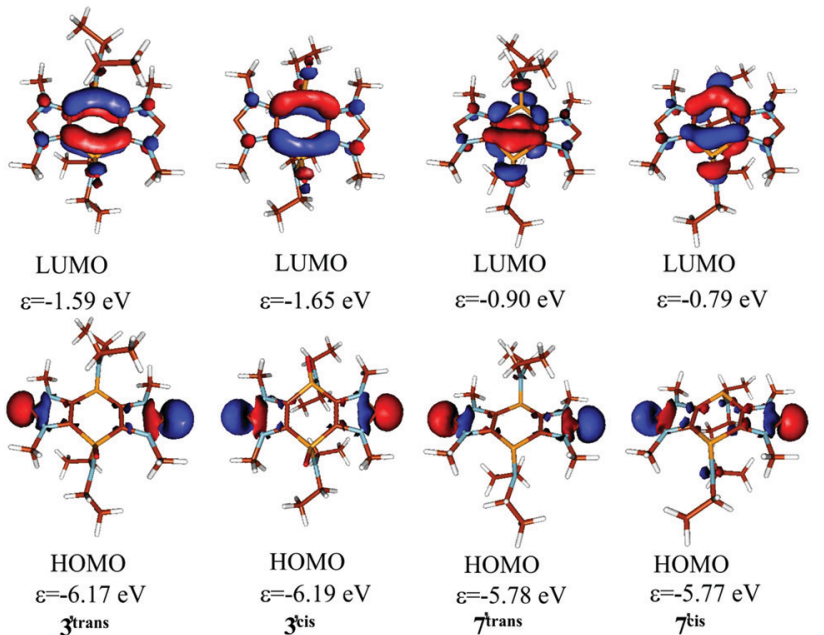

Fig. 4 Kohn-Sham frontier orbitals of $\mathbf{3}^{\prime}$ and $\mathbf{7}^{\prime}$ and their energies at B3LYP/6-31+G*//M06-2X/6-31+G* level of theory.

$3^{\prime \text { cis/trans }}$, their energy levels are somewhat stabilized (see Fig. 4). Interestingly, the stabilization of the LUMO of $3^{\text {'cis/trans }}$ with respect to $7^{\prime \text { cis/trans }}$ has little effect on the electron acceptor property of the NHC since the carbene atoms are not involved in the LUMO.

Indeed, the 35.9 (cis)/37.9 (trans) ${ }^{77} \mathrm{Se}$ chemical shift of $7^{\text {cis/trans }}$ is closer to that of 1,3-diisopropyl-imidazole-2-selone $(-3 \mathrm{ppm})$, than in case of $3^{\text {cis/trans }}(89.9 / 94.1 \mathrm{ppm}-$ see above) showing that the $\mathrm{P}(\mathrm{v})$ substitution increases somewhat the electron acceptor ability of the carbene; however, still within the known range of imidazole-2-ylidenes. ${ }^{27}$

To examine the different coordination sites of bis(NHC) $7^{\text {cis/trans }}$, reactions with coinage metals were undertaken. Thus, salts $6^{\text {cis/trans }}$ were treated with $\mathrm{M}_{2} \mathrm{O}(\mathrm{M}=\mathrm{Cu}, \mathrm{Ag})$ which resulted in the clean formation of $\mathrm{P}^{\mathrm{III} / \mathrm{III}}$-bridged bis(NHC) complexes $\mathbf{8 a}-\mathbf{b}^{\text {cis/trans }}$ (Table S2, ESI $\dagger$ ). $\mathbf{8 c}$ was obtained by metal exchange reaction using dimethyl sulfide gold(I) chloride. From the ${ }^{31} \mathrm{P}\left\{{ }^{1} \mathrm{H}\right\}$ NMR spectra of the reaction solutions it became immediately apparent that the strategy was successful and no binding had occurred to the $\mathrm{P}^{\mathrm{III} / \mathrm{III}}$ centers as their resonance signals just slightly changed compared to $6^{\text {cis/trans }}$. The formation of the $\mathrm{M}-\mathrm{C}^{2}$ bond is in good agreement with the calculated KohnSham orbitals as the lone pairs of the phosphorus do not have any contribution to the HOMO of $7^{\text {cis/trans }}$ (Fig. 4). The highfield shift of the $\mathrm{C}^{2}$ carbon resonances in the ${ }^{13} \mathrm{C}\left\{{ }^{1} \mathrm{H}\right\}$ NMR spectra indicate clearly the $\mathrm{C}^{2}$ binding of the metal(I) centers and, hence, formation

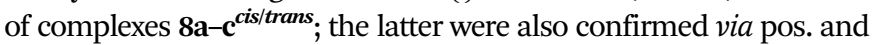
neg. ESI-MS experiments (see also ESI $\dagger$ ).

The donor properties of dicarbenes $3^{\text {cis/trans }}$ and $7^{\text {cis/trans }}$ were investigated by voltammetry. All undergo facile oxidation processes that are strongly solvent-dependent as noted previously in other cases of mono-NHCs. ${ }^{30}$ Cyclic voltammograms (CVs) measured on gold ceramic screen printed electrodes display for $3^{\text {cis/trans }} E_{\mathrm{p} 1}^{\mathrm{a}}=-0.16 \mathrm{~V} v$ s. $\mathrm{Fc}^{+/ 0}\left(\mathrm{Fc}=\right.$ ferrocene) in $\mathrm{CH}_{2} \mathrm{Cl}_{2}$ and $-0.45 \mathrm{~V}$ in THF and for $7^{\text {cis/trans }} E_{\mathrm{p} 1}^{\mathrm{a}}=-0.30 ; E_{\mathrm{p} 1}^{\mathrm{c}}=-0.42 \mathrm{~V}$; $\Delta E=120 \mathrm{mV} ; E_{\mathrm{m}}=-0.36 \mathrm{~V}$. The return peak is not observed when scanning further positive and all species display multiple 
oxidations up to the solvent limits. For $7^{\text {cis/trans }} E_{\mathrm{p} 1}^{\mathrm{a}}=-0.61 \mathrm{~V}$ in THF. There is no evidence of differentiation of the CV peaks between the cis and trans isomers. Cobaltocenium (Cc) in the form of $[\mathrm{Cc}]\left[\mathrm{PF}_{6}\right]$ was a suitable internal standard in $\mathrm{CH}_{2} \mathrm{Cl}_{2}$. Both the low first and multiple further oxidations are supported by the DFT calculations (high-energy HOMOs with carbene-C $\delta$ character and several other occupied orbitals close to the HOMOs). Moreover, the more facile oxidation of $7^{\text {cis/trans }}$ is in good agreement with the $\sim 0.4 \mathrm{eV}$ higher computed energy of the HOMOs of $7^{\prime \text { cis/trans }}$ versus $3^{\text {cis/trans. }}$.

The first examples of Janus heteroatom-bridged bis-(NHCs) with variable oxidation states of the bridging atoms are reported. The $\left(\mathrm{P}^{\mathrm{III}}\right)_{2}$ bridge induces a more basic carbene center and moreover opens the possibility of exploiting a tetratopic ligand; the latter may also hold for the $\left(\mathrm{P}^{\mathrm{V}}\right)_{2}$ bridged bis(NHC). This multigram synthetic approach may allow for the introduction of other p-block bridging elements to further expand the potential for Janus-type bis(NHC) ligands in coordination chemistry. But it may also stimulate the rapidly developing field of $\mathrm{NHC}$ main group element adduct chemistry. ${ }^{31}$

We are grateful to the University of Bonn for financial support. L. N. and R. T. B. are grateful for the Alexander von Humboldt Stiftung for the re-invitation, L. N. for the NKFIH OTKA NN 113772 and R. T. B. to NSERC-Canada.

\section{Conflicts of interest}

There are no conflicts of interest.

\section{References}

1 (a) R. Breslow, J. Am. Chem. Soc., 1957, 79, 1762-1763; (b) H. W. Wanzlick and E. Schikora, Angew. Chem., 1960, 72, 494; (c) P. Haake and W. B. Miller, J. Am. Chem. Soc., 1963, 85, 4044-4045.

2 (a) A. J. Arduengo III, R. L. Harlow and M. Kline, J. Am. Chem. Soc., 1991, 113, 361-363; (b) A. Igau, H. Grützmacher, A. Baceiredo and G. Bertrand, J. Am. Chem. Soc., 1988, 110, 6463-6466.

3 (a) V. Nesterov, D. Reiter, P. Bag, P. Frisch, R. Holzner, A. Porzelt and S. Inoue, Coord. Chem. Rev., 2018, 118, 9678-9842; (b) M. Fevre, J. Pinaud, Y. Gnanou, J. Vignolle and D. Taton, Chem. Soc. Rev., 2013, 42, 2142-2172; (c) E. Peris, Chem. Rev., 2018, 118, 9988-10031; (d) D. Munz, Organometallics, 2018, 37, 275-289; (e) R. S. Ghadwal, Synlett, 2019, 1765-1775.

4 (a) W. A. Herrmann and B. Cornils, Angew. Chem., Int. Ed. Engl., 1997, 36, 2162; (b) D. Bourissou, O. Guerret, F. P. Gabbai and G. Bertrand, Chem. Rev., 2000, 100, 39-92; (c) Y. Ryu, G. Ahumada and C. W. Bielawski, Chem. Commun., 2019, 55, 4451-4466.

5 (a) M. Poyatos, J. A. Mata and E. Peris, Chem. Rev., 2009, 109, 3677-3707; (b) P. C. Purba, S. Bhattacharyya, M. Maity, S. Mukhopadhyay, P. Howlader and P. S. Mukherjee, Chem. Commun., 2019, 55, 8309-8312; (c) S. Gonell, E. Peris and M. Poyatos, Eur. J. Inorg. Chem., 2019, 3776-3781.

6 (a) W. A. Herrmann, L. J. Goossen, C. Köcher and G. R. J. Artus, Angew. Chem., Int. Ed. Engl., 1996, 35, 2805-2807; (b) S. Diez-Gonzalez, N. Marion and S. P. Nolan, Chem. Rev., 2009, 109, 3612-3676; (c) N. E. Kamber,
W. Jeong, R. M. Waymouth, R. C. Pratt, B. G. G. Lohmeijer and J. L. Hedrick, Chem. Rev., 2007, 107, 5813-5840.

7 (a) K. M. Hindi, M. J. Panzner, C. A. Tessier, C. L. Cannon and W. J. Youngs, Chem. Rev., 2009, 109, 3859; (b) L. Mercs and M. Albrecht, Chem. Soc. Rev., 2010, 39, 1903-1912; (c) L. Mercs, A. Neels, H. Stoeckli-Evans and M. Albrecht, Dalton Trans., 2009, 7168-7178.

8 (a) A. J. Arduengo and L. I. Iconaru, Dalton Trans., 2009, 6903-6914; (b) S. Saravanakumar, M. K. Kindermann, J. Heinicke and M. Kockerling, Chem. Commun., 2006, 640-642.

9 H. V. Huynh, Coord. Chem. Rev., 2018, 118, 9457-9492.

10 (a) M. D. Sanderson, J. W. Kamplain and C. W. Bielawski, J. Am. Chem. Soc., 2006, 128, 16514-16515; (b) D. M. Khramov, V. M. Lynch and C. W. Bielawski, Organometallics, 2007, 26, 6042-6049; (c) J. I. Bates and D. P. Gates, Organometallics, 2012, 31, 4529-4536.

11 D. Mendoza-Espinosa, B. Donnadieu and G. Bertrand, J. Am. Chem. Soc., 2010, 132, 7264-7265.

12 (a) K. R. Grundy and W. R. Roper, J. Organomet. Chem., 1975, 91, C61-C64; (b) Z. Kelemen, O. Hollóczki, J. Oláh and L. Nyulászi, RSC Adv., 2013, 3, 7970-7978.

13 D. Enders and T. Balensiefer, Acc. Chem. Res., 2004, 37, 534-541.

14 R. S. Ghadwal, H. W. Roesky, M. Granitzka and D. Stalke, J. Am. Chem. Soc., 2010, 132, 10018-10020.

15 K. E. Krahulic, G. D. Enright, M. Parvez and R. Roesler, J. Am. Chem. Soc., 2005, 127, 4142-4143.

16 J. I. Bates, P. Kennepohl and D. P. Gates, Angew. Chem., Int. Ed., 2009, 48, 9844-9847.

17 D. M. Khramov, A. J. Boydston and C. W. Bielawski, Angew. Chem., Int. Ed., 2006, 45, 6186-6189.

18 (a) E. Peris, Chem. Rev., 2018, 118, 9988-10031; (b) M. Böhmer, G. Guisado-Barrios, F. Kampert, F. Roelfes, T. T. Yuan Tsai, E. Peris and E. Hahn, Organometallics, 2019, 38, 2120; (c) S. Gonell, R. G. Alabau, M. Poyatos and E. Peris, Chem. Commun., 2013, 49, 7126-7128.

19 M. Schmidtendorf, C. Schulte to Brinke and F. E. Hahn, J. Organomet. Chem., 2014, 751, 620-627.

20 (a) P. K. Majhi, G. Schnakenburg and R. Streubel, Dalton Trans., 2014， 43， 16673-16679; (b) P. K. Majhi, G. Schnakenburg, Z. Kelemen, L. Nyulászi, D. P. Gates and R. Streubel, Angew. Chem., Int. Ed., 2013, 52, 10080-10083; (c) D. Tapu, Z. McCarty and C. McMillen, Chem. Commun., 2014, 50, 4725-4728.

21 (a) A. Koner, G. Pfeifer, Z. Kelemen, G. Schnakenburg, L. Nyulászi, T. Sasamori and R. Streubel, Angew. Chem., Int. Ed., 2017, 56, 9231-9235; (b) A. Koner, Z. Kelemen, G. Schnakenburg, L. Nyulászi and R. Streubel, Chem. Commun., 2018, 54, 1182-1184.

22 I. Begum, G. Schnakenburg and R. Streubel, Dalton Trans., 2016, 46, 2955-2962.

23 N. C. Payne, A. Geissler, A. Button, A. R. Sasuclark, A. L. Schroll, E. L. Ruggles, V. N. Gladyshev and R. J. Hondal, Free Radicals Biol. Med., 2017, 104, 249-261.

24 A. G. Tennyson, R. J. Ono, T. W. Hudnall, D. M. Khramov, J. A. V. Er, J. W. Kamplain and C. W. Bielawski, Chem. - Eur. J., 2010, 16, 304-315.

$253^{\prime \text { cis/trans }}, 7^{\prime \text { cis/trans }}, 4 \mathbf{a}^{\prime}=$ calculated compounds with methyl substituents at $\mathrm{N}$.

26 L. Nyulászi, A. Forró and T. Veszprémi, Phys. Chem. Chem. Phys., 2000, 2, 3127-3129.

27 K. Verlinden, H. Buhl, W. Frank and C. Ganter, Eur. J. Inorg. Chem., 2015, 2416-2425.

28 L. Nyulászi, O. Hollóczki, C. Lescop, M. Hissler and R. Réau, Org. Biomol. Chem., 2006, 4, 996-998.

29 C. Hay, M. Hissler, C. Fischmeister, J. Rault-Berthelot, L. Toupet, L. Nyulászi and R. Reau, Chem. - Eur. J., 2001, 7, 4222-4236.

30 (a) M. Feroci, I. Chiarotto and A. Inesi, Catalysts, 2016, 6, 178; (b) M. Feroci, I. Chiarotto, F. D'Anna, F. Gala, R. Noto, L. Ornano, G. Zollo and A. Inesi, ChemElectroChem, 2016, 3, 1133-1141.

31 A. Doddi, M. Peters and M. Tamm, Chem. Rev., 2019, 119, 6994-7112. 